behaviour is chaotic. One consequence is that even if one could measure all possible variables in such a system, errors being inevitable, the ultimate behaviour would be unpredictable (sensitive dependence on initial conditions); a far cry from the predictability and control of the reductionalists. One would expect the same if, as hypothetically suggested, every neuron was replaced by a silicon chip with exactly the same properties (although measuring error would limit "exactness" as well). But all hope is not lost. Chaotic processes in systems can produce long range "order". This new "order" produces beautiful patterning believed to be responsible for the rich and varied forms in nature. It would not seem unreasonable to extend this to the rich variety and creativity of mental life. Moreover at the transitions between order and chaos this long range "order" may be characterised by long wavelength oscillations akin to the cyclical behaviour of some mental illnesses.

By viewing the mind as a result of a dynamic system one no longer needs the mind-body dichotomy, since the brain is only a part of this system. This dichotomy has plagued the area of classification in psychiatry but without it one is free to formulate psychiatric illness as a disorder of dynamic systems. Such concepts have already been applied in other areas of medicine and since many such systems have similar properties, perhaps in the areas of "healthy mind" or illness they may be usefully applied in psychiatry.

Mapperley Hospital

Nottingham NG36AA

A list of references is available on request to the author.

\section{Psychiatric disorders in mentally handicapped people}

DeAR SiRS

In some of the College Journal and Bulletin articles, mentally handicapped people are referred to as having psychiatric and behaviour disorders. For example, the Bulletin (November 1986, 10, 321-322) article on 'Psychiatric Services for Mentally Handicapped Adults and Young People' states:

"All forms of psychiatric disorder are seen although the pattern differs somewhat from that in the general population and there is a high frequency of behaviour disorders."

This statement implies that behaviour disorders are not psychiatric disorders which, of course, is not correct. Conduct disorder, in both the ICD (9th revision) and DSM-III, covers behaviour disorder.

I think we should speak of psychiatric illness and behaviour disorders under the heading of psychiatric disorders. This would avoid confusion in the minds of other professionals and managers working with us.

\section{The Manor Hospital}

V. SATKUNANAYAgam

Epsom, Surrey KT19 8NL

\section{Medical interchange}

\section{DeAR SirS}

Medical Interchange has been recently set up to facilitate the exchange of practices between doctors, both general practitioners and specialists, for short periods of time between the United Kingdom, Ireland, Australia and New Zealand. For the last ten years, I have been working as a locum consultant surgeon for four to six weeks each year in a major Sussex county hospital and have found the experience of great value and have also found that colleagues in both the United Kingdom and Australia have envied my being in a position to do this and have expressed an interest in being able to exchange their practices with colleagues for longer periods of time.

I have found a great deal of interest in this idea from editors of medical journals and newsletters in the four countries concerned and feature articles on the enterprise are about to start appearing. I have also placed advertisements in appropriate journals in the countries involved.

I would like to ask that you bring this enterprise to the attention of your members as I believe this would be to the advantage not only of Medical Interchange but also of the individuals who may well be delighted with the opportunity of an exchange.

The registration and immigration requirements are quite complex and it is the intention of Medical Interchange to carry out whatever is possible to comply with the formalities but quite clearly there are some which must be attended to personally by the doctors concerned. All details will be provided concerning these requirements.

\section{Medical Interchange \\ 100 Lurline Street}

Richard J. Crane

Katoomba, NSW 2780, Australia

P.S. I have recently received an enquiry from a psychiatrist in Manly, Sydney, New South Wales who has expressed an interest in exchanging his practice with that of a colleague in the United Kingdom for a period of some months.

\section{DeAR SIRS}

Enclosed with the September 1990 issue of the Psychiatric Bulletin was a notice about registration of psychiatrists with the General Medical Council as "trained". I am sure that other overseas members of the College would appreciate a Bulletin article explaining the purpose of the new register. Unless 